\title{
Prática interdisciplinar sobre alimentação utilizando a metodologia de Rotação por Estações na educação infantil
}

\author{
Interdisciplinary practice on food using the Rotation by Stations \\ methodology in kindergarten
}

\author{
Carolina Bento Pereira Gonçalves ', Gisele Lángaro Soares "
}

\section{RESUMO}

Em dias atuais, a chamada era digital influencia todos os jovens, tanto na maneira de agir como de ver o mundo, de socializar e de aprender. As escolas ainda presas no método tradicional de ensino, sem acesso à tecnologia digital ou a nenhum outro aparato ou metodologia tecnológica, necessitam quebrar esse paradigma e incluir em seus processos métodos de ensino inovadores, que melhorem de forma significativa o aprendizado das crianças. Este artigo tem como objetivo avaliar uma prática de ensino interdisciplinar utilizando a técnica de Rotação por Estações para trabalhar o tema de alimentação saudável, abrangendo os componentes curriculares Português, Inglês e Ciências. Para isso, foi desenvolvido um plano de atividade, o qual foi posteriormente aplicado aos alunos do pré-escolar de uma escola particular no município de São Gabriel, RS. Trata-se de uma pesquisa-ação, com observação participante e com análise de documentos produzidos pela professora e coordenadora da escola. A análise dos resultados evidencia os benefícios da uma atividade interdisciplinar, bem como o aumento da participação e curiosidade dos alunos. Trabalhar conteúdos pedagógicos de forma interdisciplinar fornece recursos para que as crianças desenvolvam o ensino aprendizagem de forma autônoma, além de melhorar a interação com o grupo e a dinâmica em sala de aula. O uso da técnica de Rotação por Estações confirmou que um processo de aprendizagem se realiza de fato quando o aluno aprende de forma mais personalizada e autônoma com a valorização de suas habilidades e competências e tendo o professor como facilitador do processo de aprendizagem.

Palavras-chave: Interdisciplinar; Rotação por Estações; Tecnologia; Alimentação saudável; Metodologias de ensino.

\section{ABSTRACT}

Nowadays, the digital age affects all the young people, the way they act and see the world, socialize and learn. Schools are stuck in the traditional teaching method, without access to technology or any other instrument or methodology, they need a paradigm shift, including in their teaching groundbreaking interdisciplinary teaching techniques that improves kid's learning in a very significant way. The main objective of the present article is to evaluate an interdisciplinary teaching practice using Station Rotation technique to

\footnotetext{
' Bacharel em Administração, Acadêmica do curso de Especialização em Práticas de Ensino Interdisciplinares, Universidade Federal do Pampa. E-mail: carolinabpg@yahoo.com.br.

" Mestre em Ensino de Línguas, Docente do curso de Especialização em Práticas de Ensino Interdisciplinares, Universidade Federal do Pampa. E-mail: giselelangaro@hotmail.com. ORCID: https://orcid.org/0000-0003-4326-2417.
} 
develop healthy eating habits, including Portuguese, English and Science. An activity plan was developed and applied to kindergarten students of a private School in the city of São Gabriel, RS. It's about a research-action with participant observation and data analysis of documents written by the teacher and the school coordinator. The analysis shows the benefits of an interdisciplinary activity, such as the participation and curiosity of the students. Working pedagogical contents in an interdisciplinary way provides the kids resources which develop teaching-learning in an independent approach, besides improving the interaction as well as improving group interaction and classroom dynamics. The use of the Station Rotation technique confirmed that a learning process takes place when the student learns in a more personalized and autonomous way by valuing their skills and competences and having the teacher as a facilitator of the learning process.

Keywords: Interdisciplinary; Station Rotation; Technology; Healthy eating habits; Teaching methodology.

\section{INTRODUÇÃO}

O modelo de aprendizagem tradicional, separado por conteúdos, sem relação entre as disciplinas e centralizado no professor vem sendo analisado e contraposto às novas tecnologias e metodologias de ensino que possibilitam ao aluno um processo de aprendizagem totalmente inovador e diferente, fazendo uso da tecnologia de forma que a mesma se torne uma parte significativa e atrativa, bem como metodologias que possibilitam ao aluno desenvolver o senso crítico e a capacidade de resolver questões e encontrar soluções de forma natural, sem apenas receber o conteúdo das aulas expositivas e resolver exercícios.

As escolas devem atender e se adaptar às novas demandas de ensino proporcionando aprendizagem de qualidade, com metodologias inovadoras, com profissionais capacitados e material atrativo alinhado com o perfil dos alunos, como forma de inserir o processo de aprendizagem no cotidiano e trabalhar com situações e problemas que os ajudem em suas necessidades.

O método de Rotação por Estações, segundo Oliveira e Pesce (2017) não perde de vista o rigor metodológico, porém insere os estudantes no centro do processo educativo, tornando as aulas mais estimulantes, prazerosas e promissoras.

O ensino interdisciplinar por sua vez, unifica os conteúdos em torno de uma problemática em comum que possibilita ao estudante trabalhar e refletir sobre suas 
experiências e resultados. Fazenda (2011 p.75) afirma que somente a interdisciplinaridade "[...] irá possibilitar uma certa identificação entre o vivido e o estudado, desde que o vivido resulte da interrelação de múltiplas e variadas experiências".

O ensino híbrido vem ganhando cada vez mais espaço nas abordagens pedagógicas, pois permite que o aluno trabalhe de forma mais independente, sem a presença física do professor. Com a Rotação por Estações é possível trabalhar diferentes assuntos em cada estação, assim o professor consegue mapear as dificuldades e visualizar o ritmo de cada aluno. Conforme Andrade e Souza

(2016) a rotação por estações é:

Um processo de aprendizagem que se realiza de fato, de maneira diferente, com a vantagem de o aluno aprender de forma mais personalizada, com autonomia para desenhar, programar seu aprendizado na valorização de suas habilidades e competências, tendo o professor como facilitador do processo de aprendizagem. (ANDRADE E SOUZA, 2016 p.9)

\subsection{Interdisciplinaridade na educação}

A interdisciplinaridade é uma abordagem de ensino não preconceituosa, em que todo o conhecimento é igualmente importante, onde o conhecimento pessoal anula-se ao saber universal (Fazenda, 2011). Portanto, pode-se entender interdisciplinaridade como forma de trabalhar os conteúdos, integrando conhecimentos de cada área com um objetivo em comum. É uma metodologia de ensino aprendizagem inovadora oposta ao ensino tradicional segregado por áreas de conhecimento e tendo o professor como papel central no ensino. A interdisciplinaridade permite ao aluno ser o protagonista do seu aprendizado, desenvolvendo o senso crítico e melhorando seu poder de reflexão. Ainda sobre a interdisciplinaridade pedagógica, Fazenda (2008) afirma: 
Quando a escola se abre para um novo olhar para a educação que ministra, a possibilidade de elaborar um projeto interdisciplinar começa a tomar forma, tornando-se mais concreta. A interdisciplinaridade passa então a não ser mais vista como negação da disciplina. Ao contrário, é justamente na disciplina que ela nasce. Muito mais que destruir as barreiras que existem entre uma e outra, a interdisciplinaridade propõe uma superação (FAZENDA, 2008 p.94).

Compartilhando desta mesma visão Gattás e Furegato (2007) afirmam que o estudo da interdisciplinaridade é uma ferramenta de superação da fragmentação do pensamento e da visão parcelar do mundo. Em seu trabalho sobre interdisciplinaridade Thiesen (2008) menciona que estudos estão sendo feitos por autores que tentam resgatar a totalidade de conhecimento e que também analisam criticamente o modelo positivista das ciências. O autor também conclui:

A interdisciplinaridade está impulsionando transformações no pensar e no agir humanos em diferentes sentidos. Retoma, aos poucos, o caráter de interdependência e interatividade existente entre as coisas e as ideais, resgata a visão de contexto da realidade, demonstra que vivemos em uma grande teia de interações complexas e recupera a tese de que todos os conceitos e teorias estão conectados entre si." (THIESEN, 2008, p.9)

\subsection{Ensino Híbrido: Rotação por Estações}

O sistema tradicional de ensino não satisfaz a demanda dos alunos da atualidade por um modelo de ensino inovador, compreendendo essa necessidade, surgiu o ensino híbrido ou Blended Learning, um modelo de ensino aprendizagem que mistura o modelo tradicional com o ensino online Andrade e Souza (2016). De acordo com Oliveira e Pesce (2018) a demanda por um novo modelo de ensino culminou com o surgimento da internet:

Tendo a internet como infraestrutura básica, as relações de tempo e espaço foram profundamente ressignificadas, o acesso à informação democratizou-se e as novas possibilidades de construção de conhecimentos também foram ampliadas. Essa nova dinâmica social é mercada pela conectividade, mobilidade, interatividade, compartilhamento, simultaneidade e velocidade das informações e da comunicação, e certamente a escola não pode se manter apartada desse novo conceito" (OLIVEIRA E PESCE, 2017, p.107). 
Como uma das práticas do ensino híbrido, há a técnica da Rotação por Estações, na qual os alunos devem percorrer as ilhas ou estações de trabalho. Cada estação possui uma atividade diferente e pelo menos uma das estações deve fazer uso das novas tecnologias da informação. O professor elabora o conteúdo das estações conforme um cronograma, as atividades podem ser feitas individualmente ou em grupo e podem abordar diferentes assuntos como leitura, elaboração de projetos, resolução de problemas escrita, entre outros. Após certo tempo combinado previamente com os alunos, eles encerram suas atividades na estação e passam para a próxima, por isso as estações são independentes, mas estão relacionadas com o mesmo tema ou objetivo geral. Dessa maneira o aluno é estimulado a aprender de forma independente e colaborativa e ainda recebe atenção de forma individualizada pelo professor, que consegue sair do centro da sala com o uso desse método de ensino aprendizagem (Oliveira e Pesce, 2017).

A figura 1 demonstra a aplicação da Rotação por Estações, neste caso a imagem ilustra três estações. É válido lembrar que esse modelo de ensino aprendizagem pode ser aplicado em qualquer disciplina e pode ser trabalhado com diferentes conteúdos.

\section{Figura 1 - Modelo de ensino híbrido Rotação por Estações}

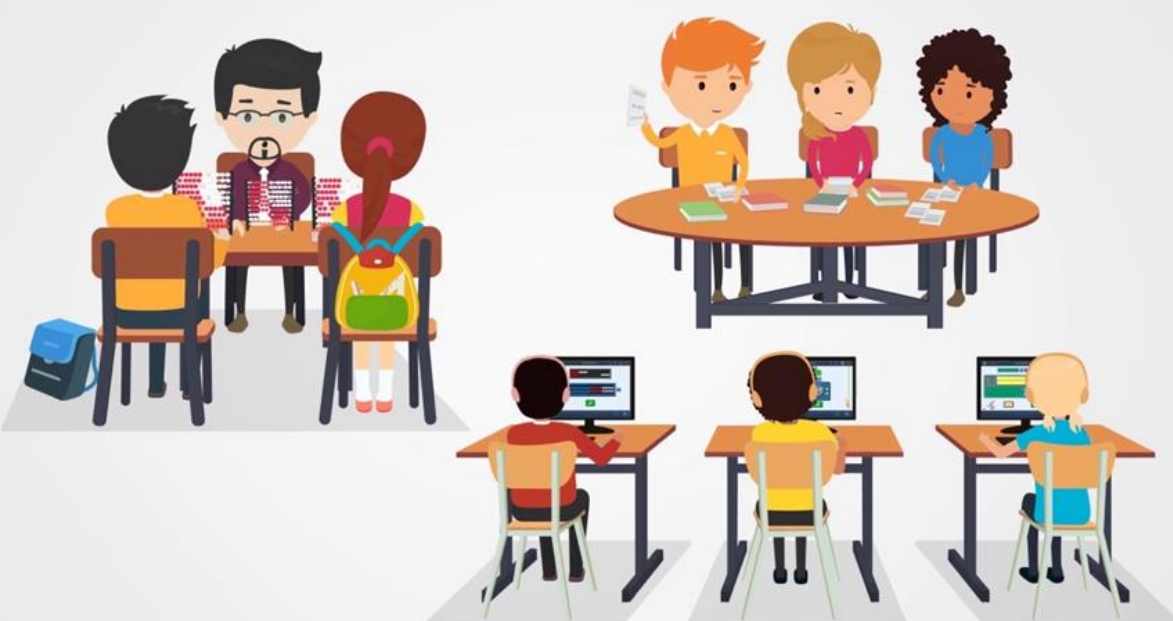

Fonte: https://www.youtube.com/watch?v=JgN2M09i9yl. Acesso em: 1 de dezembro de 2019. 


\section{PROCEDIMENTOS METODOLÓGICOS}

Neste trabalho, os 9 alunos de uma turma da pré-escola de uma escola particular do município de São Gabriel, RS, foram agrupados em estações com atividades diferentes e independentes, mas que se relacionam por um assunto em comum: a alimentação saudável. Trata-se de uma pesquisa-ação, com observação participante da atividade, com análise de documentos produzidos pela professora e coordenadora da escola. A prática foi planejada e aplicada juntamente com a professora da escola, o tema abordado surgiu do questionamento sobre a necessidade de familiarizar as crianças com a alimentação saudável, visto que a escola tem o dia da fruta, porém essa data incentiva os alunos a consumirem frutas em apenas um dia na semana, e não ao consumo diário e habitual. Antes da prática, a professora da turma conversou com os alunos sobre seus hábitos alimentares, momento este em que foi possível observar que muitos possuíam alguns conhecimentos sobre o assunto e citaram vários alimentos como saudáveis, porém não incluíam esses alimentos em sua dieta. De acordo com Ramos e Stein (2000):

A tendência das preferências alimentares das crianças na idade pré-escolar conduz ao consumo de alimentos com quantidade elevada de carboidrato, açúcar, gordura e sal, e baixo consumo de alimentos como vegetais e frutas, se comparados às quantidades recomendada" (RAMOS E STEIN, 2000, p.230)

Percebendo-se a necessidade de incentivar o consumo de alimentos saudáveis com a turma e de desenvolver e trabalhar o conteúdo escolar, optou-se por uma prática de ensino interdisciplinar utilizando a Rotação por Estações. Tal prática incluiu conteúdos dos componentes curriculares Português, Inglês e Ciências divididos em três estações. Andrade e Souza (2016) explicam que a prática deve seguir um roteiro pré-estabelecido, no qual os alunos passam um tempo imersos em cada estação e que pelo menos uma estação deve ser on-line. 
O roteiro pré-estabelecido foi divido em três estações:

Estação número 1: os alunos da pré-escola iniciam o processo de alfabetização nesta etapa, já conseguem identificar todas as letras do alfabeto e ler algumas palavras. Por isso essa estação foi pensada para desenvolver o componente curricular Português. A atividade proposta foi separar as figuras de alimentos saudáveis e não saudáveis e a partir deste momento relacionar as letras iniciais de cada alimento com as imagens.

A Figura 2 mostra a aplicação da estação número 1, na qual os alunos, com a ajuda da professora, estão relacionando as letras do alfabeto com as imagens depois de terem separado os alimentos saudáveis.

Figura 2 - Alunos da pré-escola relacionando as letras do alfabeto com as imagens de alimentos saudáveis. Atividade do componente curricular Português, correspondente à estação número 1 do sistema de Rotação por Estações

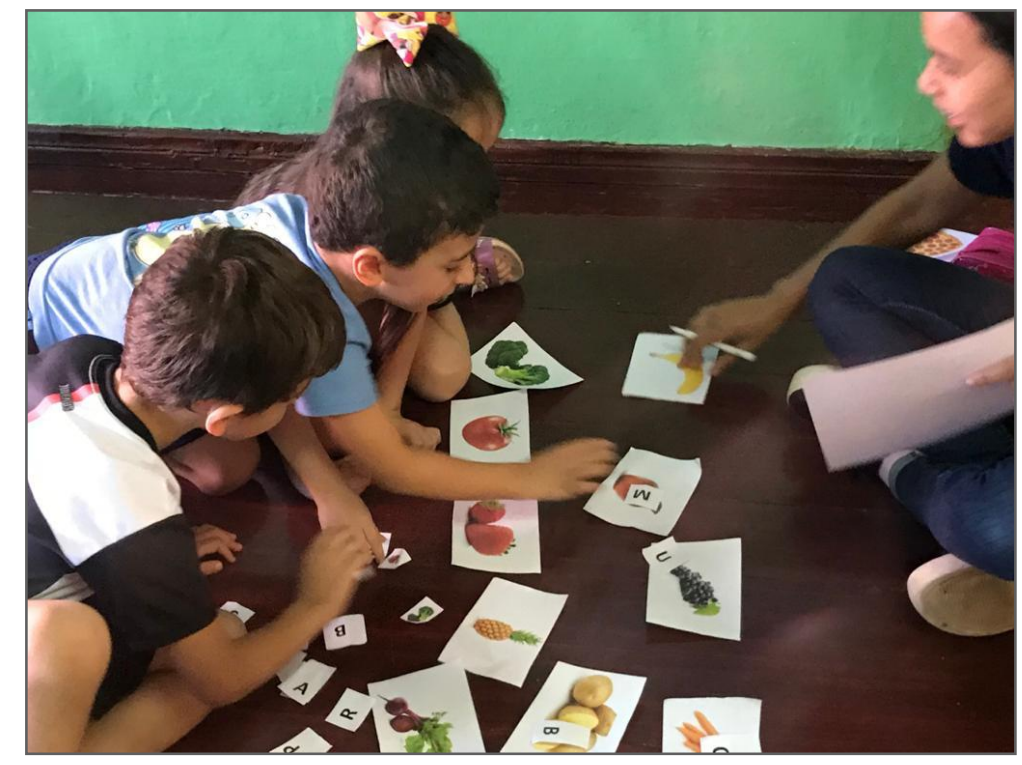

Fonte: Arquivo Pessoal (2019).

Estação número 2: Nesta estação os alunos assistiram a um vídeo duas vezes, o qual abordava as frutas e vegetais em inglês, e juntos repetiram as palavras e adquiriram um novo vocabulário. Após o vídeo, os alunos participaram de um jogo da 
memória com as frutas e vegetais em que praticaram em voz alta o nome das figuras cada vez que viravam a carta.

Na Figura 3 vemos os alunos na estação número 2, na qual necessitavam de um elemento online para realizar a atividade.

Figura 3 - Alunos da pré-escola realizando atividade do componente curricular Inglês correspondente à estação número 2 do sistema de Rotação por Estações. (A) Vídeo em inglês sobre frutas e vegetais. (B) Jogo da memória com os alimentos vistos no vídeo

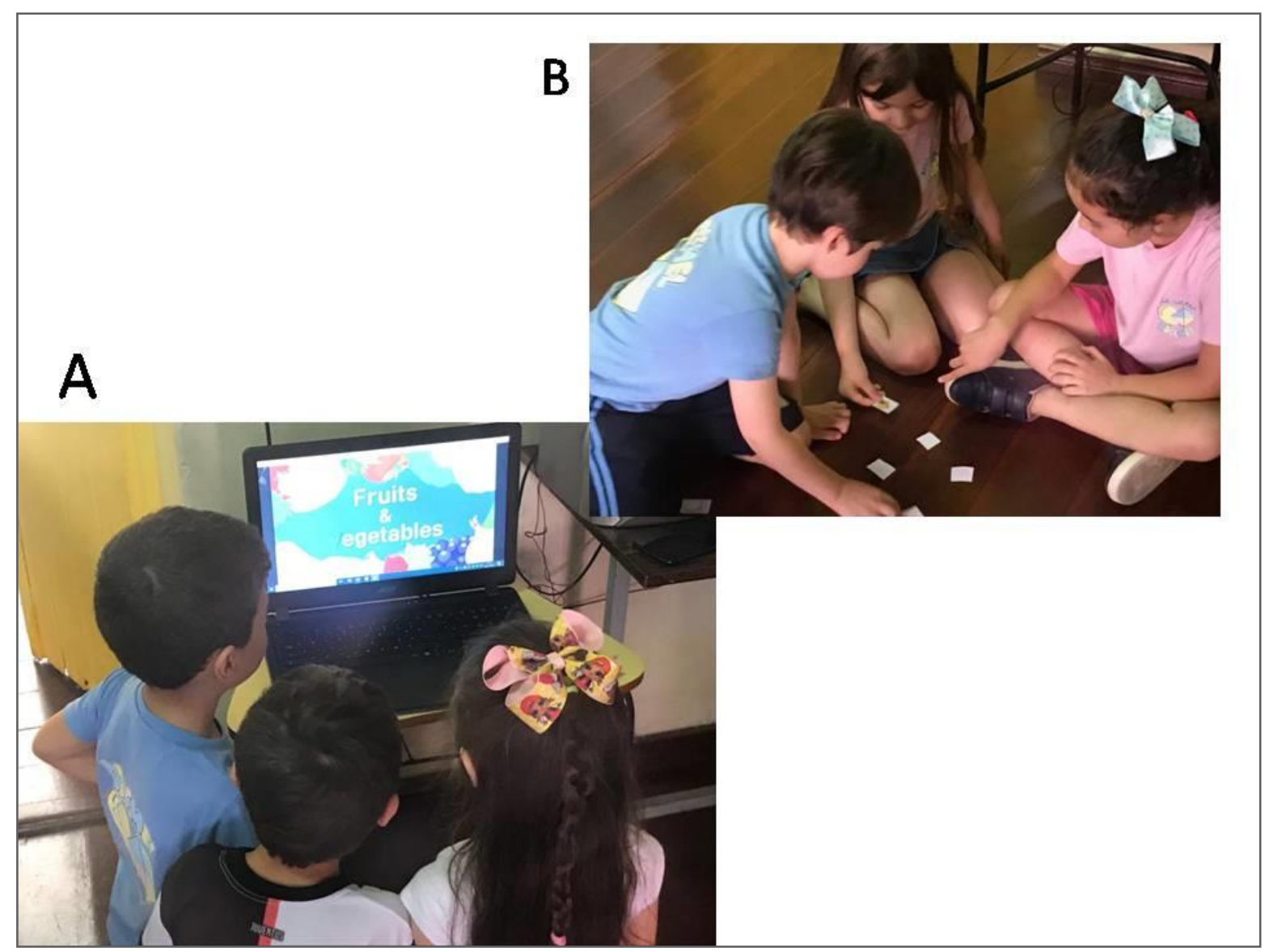

Fonte: Arquivo Pessoal (2019).

Estação número 3: Nesta etapa os alunos participaram de uma degustação às cegas. Cada um deveria experimentar algumas frutas e verduras e depois desenhar o que mais gostou de comer e mostrar para os colegas. Alguns dos alunos durante a conversa com a professora admitiram não gostar de certos alimentos e, em alguns 
casos, afirmavam não gostar sem sequer terem experimentado o alimento. Foram oferecidos: cenoura, beterraba, batata, brócolis, tomate, uva, abacaxi, morango e banana.

A figura 4 mostra a última estação, na qual os alunos participam de uma degustação às cegas podendo provar diversas frutas e vegetais, a fim de ampliarem seus paladares em relação a alimentos saudáveis.

Figura 4 - Aluno da pré-escola realizando a degustação às cegas de frutas e vegetais. Atividade do componente curricular Ciências correspondente à estação número 3 do sistema de Rotação por Estações. (A) aluno participando da degustação às cegas. (B) Crianças desenhando as frutas ou vegetais que mais gostaram de comer

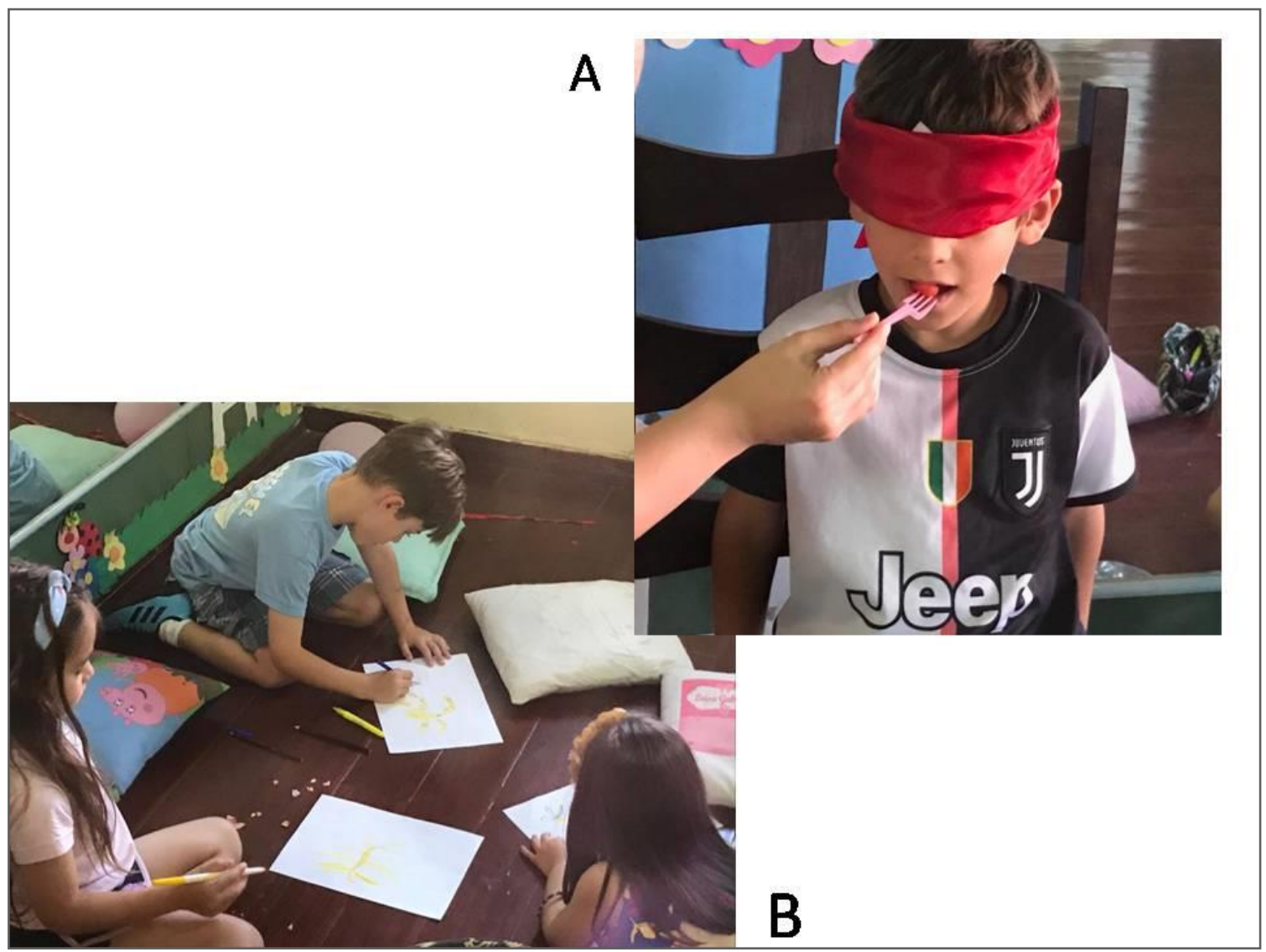

Fonte: Arquivo Pessoal (2019). 


\section{RESULTADOS E DISCUSSÃO}

Antes de iniciarmos a atividade, a professora conversou com os alunos sobre os hábitos alimentares de cada um, se as crianças conheciam ou gostavam de comer frutas e verduras. Com esse primeiro relato foi possível observar que muitos alunos disseram não gostar de comer esses alimentos, e após serem questionados se alguma vez já haviam experimentado, algumas crianças afirmaram que nunca haviam provado. Por outro lado, alguns alunos da turma já estavam familiarizados com o consumo desses alimentos, e por isso mostraram naturalidade na experiência da estação três, ao contrário dos alunos que não apresentavam conhecimento ou consumo regular de frutas e verduras, com eles foi possível observar certo nervosismo sobre o que iriam experimentar.

A escola, a fim de incentivar a alimentação saudável entre as crianças, adotou o dia da fruta, porém o consumo de frutas e verduras deve ser incentivado diariamente, com o objetivo de realmente conscientizar as crianças sobre suas escolhas. De acordo com Santos, Silva e Pinto (2018):

Apesar das crianças em idade pré-escolar já estarem expostas a temáticas sobre alimentação, necessitam de aumentar as suas competências, como consumidores informados, para que estejam aptas a escolher os seus próprios alimentos numa sociedade onde existe uma grande variedade de alimentos disponíveis e de fácil acesso, para que não se deixem influenciar pelas ações das pessoas que as rodeiam e pela pressão da publicidade que as envolve diariamente". (SANTOS, SILVA e PINTO, 2018 p.19)

É inegável o acesso à tecnologia e à informação, especialmente entre as crianças que nasceram inseridas no conceito tecnológico, por isso quando apresentadas à estação dois, as crianças não demonstraram vergonha ou timidez, todas agiram naturalmente frente ao elemento novo que era o inglês. Muitos já conheciam algumas palavras devido aos jogos e vídeos disponíveis na internet, por isso realizaram tranquilamente a atividade proposta. De acordo com o relato da coordenadora da escola, as crianças gostaram e se estimularam muito com a 
atividade interdisciplinar, visto que não haviam feito nada parecido na escola. É possível pensar em diversas outras abordagens interdisciplinares com as crianças, especialmente porque existe criatividade em abundância quando se trabalha com o ensino infantil. Crianças gostam de saber o porquê das coisas e aprender de forma interdisciplinar proporciona uma aprendizagem efetiva, utilizando a criatividade das crianças relacionada ao contexto em que elas vivem, universaliza o saber, aprimora a capacidade de resolver questões de forma mais independente e ainda possibilita ao aluno a sair da sua zona de conforto e da maneira tradicional do ensino, que por muitas vezes coloca amarras nas ferramentas e habilidades que a interdisciplinaridade tende a libertar.

De acordo com a coordenadora da escola, a prática de ensino interdisciplinar realizada com os alunos proporcionou um aprendizado mais dinâmico, além de ampliar as experiências e o hábito saudável nas crianças, pois uma alimentação correta é a base para uma vida física e mental saudável. A professora ainda classificou a experiência como lúdica e atraente, pois ampliaram seu vocabulário, reforçaram o que haviam aprendido em aula e refletiram sobre o que é realmente uma alimentação saudável.

\section{CONCLUSÕES}

A partir da realização de uma prática de ensino interdisciplinar utilizando o sistema de Rotação por Estações foi possível perceber que a dinâmica dentro da sala foi alterada, os alunos conseguiram aprender passando por cada estação, onde aprenderam diferentes conteúdos interligados por um objetivo em comum, a alimentação saudável. O ensino aconteceu de forma natural, dinâmica e fora dos padrões tradicionais, onde as crianças foram os protagonistas de sua aprendizagem.

Planejar com antecedência um cronograma que beneficie os alunos ou que aborde um assunto que faça parte do contexto e realidade que cada um está inserido, 
de forma interdisciplinar, prepara essas crianças para lidar com as adversidades e com as situações diárias, desenvolvendo um senso de autonomia e capacidade para resolver seus próprios problemas, refletindo de forma crítica e levantando questionamentos sobre o que acontece ao seu redor. Uma atividade interdisciplinar pedagógica enriquece não somente a parte curricular dos alunos, mas também enriquece suas experiências e desenvolve diversas habilidades positivas que extrapolam os limites do ensino tradicional, permitindo que esse cidadão consiga pensar de forma não convencional e de maneira inovadora.

Através da observação participante conseguiu-se notar um grande interesse em realizar atividades fora do convencional. Segundo conversa com a professora, os alunos não haviam participado de nenhuma experiência interdisciplinar ou utilizado o modelo de Rotação por Estações e ainda sim, realizaram naturalmente todas as etapas da atividade, ajudando uns aos outros naquilo que não conseguiam realizar sozinhos. Pode-se afirmar que a atividade afetou a interação do grupo, excluindo o caráter egocêntrico do modo tradicional, e desenvolvendo o senso de grupo, este último muito presente na estação número três, pois os alunos encorajavam seus colegas a experimentar os alimentos e vibrando cada vez que isso acontecia.

De modo geral a atividade interdisciplinar aplicada na escola trouxe resultados positivos, possibilitando o aumento e desenvolvimento de habilidades imprescindíveis nos dias de hoje, bem como um bem-estar geral em sala de aula, culminando com o pedido dos alunos por mais atividades semelhantes. Seria muito positivo se a interdisciplinaridade fosse aplicada ao dia a dia dos alunos, como forma de ver e sentir o mundo como um todo, vivenciar situações reais e ser capaz de resolvê-las, bem como alterar a dinâmica em sala de aula, transformando o aluno no sujeito principal na aprendizagem e o professor como um mediador, fazendo o papel de orientador e com liberdade para personalizar o ensino aprendizagem de cada um, 
fazendo com que esse processo de torne muito mais atraente, dinâmico, prático e inovador.

\section{AGRADECIMENTOS}

As autoras agradecem ao prof. Valdir Marcos Stefenon (Universidade Federal de Santa Catarina) pelas discussões relacionadas a este trabalho e à escola onde o estudo foi realizado.

\section{REFERÊNCIAS}

ANDRADE, M.C., SOUZA, P. (2016). Modelos de Rotação do Ensino Híbrido: Estações de trabalho e sala de aula invertida. E-tech: Tecnologias para Competitividade Industrial, Florianópolis, v.9, n. 1, 2016.

FAZENDA, I.C. (2011). Integração e Interdisciplinaridade no Ensino Brasileiro: Efetividade ou Ideologia. $6^{\circ}$ edição. São Paulo: Editora Loyola, 2011.

GATTÁS, M.L., FUREGATO, A.R. A interdisciplinaridade na educação. Revista da Rede de Enfermagem do Nordeste. Fortaleza, v.8, num. 1, p 85-91, jan-fev, 2007.

OLIVEIRA, M.I., PESCE, L. (2017). Emprego do modelo rotação por estações para o ensino de língua portuguesa. Teccogs: Revista Digital de Tecnologias Cognitivas, TIDD/ PUC-SP, São Paulo, n.16, p. 103-118, jul-dez.2018.

RAMOS, M, STEIN, L. (2000). Desenvolvimento do Comportamento Alimentar Infantil. Jornal da Pediatria. Rio de Janeiro, v. 76, p.229-237.

SANTOS, B., SILVA, C., PINTO, E. (2018). Importância da Escola na Educação Alimentar em Crianças do Primeiro Ciclo do Ensino Básico - Como ser mais eficaz. Acta Portuguesa de Nutrição. Porto, v.14, p. 18-23, set 2008.

THIESEN, J. A Interdisciplinaridade como um movimento articulador no processo ensino-aprendizagem. Revista Brasileira de Educação, Rio de Janeiro, v. 13, n. 39, set-dez, 2008. 